Conclusion In collaboration with others and several different approaches, the hospice is able to offer choice and access to care for the homeless population it serves; therefore transforming experience for this marginalised group.

\section{P-36 HOMELESSNESS AND END OF LIFE CARE: IMPROVING PARTNERSHIP WORKING}

Catherine Thompson, Janet Hawksworth, Jayne Bargh, Sadaf Adnan. Kirkwood Hospice, Huddersfield, UK

\subsection{6/bmjspcare-2018-hospiceabs.61}

The aim of this project has been to engage with services who have traditionally not worked in partnership with the hospice, in order to jointly identify ways of integrating services to better support vulnerable adults. By up-skilling and increasing confidence for multi-disciplinary professionals both internally and externally, we hope to both widen access to our services but also to develop compassionate communities, in line with the Ambitions guidance.

Aims

- Improving reach

- Challenge pre-conceived ideas surrounding end of life care and dispel myths

- Identify opportunities to work in partnership to support hidden and isolated carers

- Increase awareness of the interconnections between end of life care and agencies supporting those who are more likely to be faced with health and social inequality.

- Develop practical guidance to improve earlier identification and signposting.

A workshop was held in February 2018, within the hospice, with attendance from 11 local organisations supporting those who are homeless within Kirklees. This was an engaging and thought provoking event, with many attendees acknowledging the gaps in promoting holistic end of life care.

There was recognition of the value of working together to understand and share each other's specialism and skills but also the need for external improvement in professionals' confidence in end of life conversations. Another area of focus was the need to improve bereavement support and skills.

A training and education plan is currently in development, with the initial focus on developing and piloting self-management sessions for those with liver failure. A clinical ambassador programme is also planned to be launched, with input from organisations attending workshop.

Considerations The role of the hospice in offering 'outreach'. Importance of advocacy for individuals less likely to actively engage with end of life care services. Person-centred care and respecting people's decisions, especially if other priorities come before seeking healthcare.

\section{P-37 LEARNING DISABILITY COMMUNITY COLLABORATION PROJECT FOR PEOPLE WITH PALLIATIVE CARE NEEDS}

Gemma Allen. The Mary Stevens Hospice, Stourbridge, UK

\subsection{6/bmjspcare-2018-hospiceabs.62}

Background People with a learning disability (LD) are three times more likely to die at a younger age than the overall population (Heslop, Blair, Fleming, et al., 2013). Furthermore, they may experience inadequate end of life care through providers not recognising or considering individual needs (Care Quality Commission, 2016).

Two LD champions were appointed, to examine how we support more people in the community from this marginalised group.

Aim(s) Increase accessibility for people with LD to receive coordinated, personalised, end of life care. Identify gaps in knowledge of hospice staff.

Methods Hospice peer review conducted by LD self-advocacy group. Opinions of LD providers and professionals canvassed. Presentations delivered through community engagement emphasising objectives.

\section{Outcomes}

- Information pack produced, and training developed for hospice staff and volunteers. End of life care education scheduled for LD professionals.

- Easy- read literature review, funds granted to adapt hospice information.

- 24 LD care home staff accessed 'Palliative Care Champions' training.

- Interactive Dying Matters event for people with profound, multiple LD.

- Staff trained in Makaton.

- University partnership creating diversity/inclusion initiatives and research proposals.

- Development of regional LD palliative care network.

- Recognised as a 'Safe Place.'

Feedback from people with learning disabilities:

'...they are true learning disability champions, passionate and committed to getting the service right for everyone.'

'The hospice is already a friendly place and I can see it getting more disability friendly.'

Conclusions The project has addressed inequalities from this marginalised group's experience. The programme is ongoing, ensuring people with a LD receive fair, accessible, inclusive end of life care, now and in the future.

\section{P-38 SUPPORTING PEOPLE WITH LEARNING DISABILITIES AT END OF LIFE: A TRAINING PROGRAMME}

Nicola Le Prevost, Tracey Rose, Rosalyn Chapman. Kent Community Health NHS Foundation Trust, Maidstone, UK

\subsection{6/bmjspcare-2018-hospiceabs.63}

Background The project arose from personal experience/reflection resulting from caring for someone with a learning disability [LD] at the hospice. Lack of support and knowledge from the involved services contributed to an outcome in not meeting the person's wishes to be cared for at 'home', which should have been possible.

Reports and enquiries indicate the inequity in health and need for end of life care: health care is not equitable (Confidential Inquiry into Premature Deaths of People with Learning Disabilities, 2013); staff caring for people with LD require development of end of life care knowledge and skills (Palliative Care for People with Learning Disabilities Network, 2017/18; Care Quality Commission, 2016; NHS National End of Life Care Programme, 2011). 